\title{
Thyroid Functions and Thyroid Auto-Antibodies in Pediatric Systemic Lupus Erythematosus Patients: A Study from Bangladesh
}

\author{
Satya Narayan Chaudhary ${ }^{1,}$, , Shahana Akther Rahman ${ }^{1}$, Mohammad Imnul Islam ${ }^{1}$, \\ Suraiya Begum ${ }^{1}$, Manik Kumar Talukdar ${ }^{1}$, Md Israque Hossain Ansari' ${ }^{2}$, Mizanul Hasan ${ }^{2}$ \\ ${ }^{1}$ Department of Pediatrics, Bangabandhu Sheikh Mujib Medical University (BSMMU), Dhaka, Bangladesh \\ ${ }^{2}$ National Institute of Nuclear Medicine \& Allied Sciences (NINMAS), Bangabandhu Sheikh Mujib Medical University, Dhaka, Bangladesh
}

\section{Email address:}

drsatyan@gmail.com (S. N. Chaudhary), shahana2pd@yahoo.com (S. A. Rahman), imon27@gmail.com (M. I. Islam), Suraiyadr07@yahoo.com (S. Begum), talukder.manik@gmail.com (M. K. Talukdar), israque_h@yahoo.com (M. I. H. Ansari), drhasan_m@yahoo.com (M. Hasan)

\section{To cite this article:}

Satya Narayan Chaudhary, Shahana Akther Rahman, Mohammad Imnul Islam, Suraiya Begum, Manik Kumar Talukdar, Md Israque Hossain Ansari, Mizanul Hasan. Thyroid Functions and Thyroid Auto-Antibodies in Pediatric Systemic Lupus Erythematosus Patients: A Study from Bangladesh. American Journal of Clinical and Experimental Medicine. Vol. 3, No. 5, 2015, pp. 207-212. doi: 10.11648/j.ajcem.20150305.12

\begin{abstract}
Background: Thyroid dysfunction may be associated in pediatric SLE cases and may present as euthyroid, subclinical hypothyroid, hypothyroid or hyperthyroid states. Aim of this study was to assess thyroid functions (serum T3, T4, TSH) and thyroid antibodies (anti-thyroid Peroxidase and anti-thyroglobulin) in pediatric SLE patients. Methods: It was across sectional study. Pediatric SLE (pSLE) patients who fulfilled the American College of Rheumatology 1997revised classification criteria for SLE were enrolled in this study. Sixteen apparently healthy children were enrolled in the study as reference group. Disease activity was measured by systemic lupus erythematosus disease activity index (SLEDAI). Serum T3, T4, TSH and auto-antibodies including, anti-thyroid peroxidase (anti-TPO) and anti- thyroglobulin (anti-TG) were measured by radio-immuno assay (RIA) method in the National Institute of Nuclear Medicine \& Allied Sciences, BSMMU, Dhaka. Data were analyzed by SPSS for window version 16 which included descriptive statistics, Man-Whitney test and Fisher exact test. Results: Among a total number of 50 pSLE cases, 41 (82\%) cases had euthyroid state, 4 had subclinical hypothyroidism, 3 had hypothyroidism and 2 patients had euthyroid sick syndrome. All the cases of reference group were in euthyroid state. Anti-thyroid peroxidase (TPO) antibody was positive in 24 pSLE cases and anti-thyroglobulin (TG) antibody was positive in 16 patients. Thyroid disorder was present in 9 cases and 7 of them had positive anti-TPO antibody. Conclusion: Thyroid disorders and presence of thyroid auto antibodies were common in pSLE patients. Anti-TPO positivity was more common than Anti-TG positivity.
\end{abstract}

Keywords: Pediatric SLE, Triidothyronine, Thyroxine, TSH, Anti- thyroid Peroxidase, Anti- thyroglobulin

\section{Background}

Systemic lupus erythematosus (SLE) is a chronic autoimmune disease characterized by multisystem inflammation and the presence of circulating auto-antibodies directed against self antigens leading to inflammatory damage of many target organs including the skin, joints, kidneys, blood-forming cells, blood vessels and the central nervous system. SLE in children is generally more acute and has severe and more widespread organ involvement than in adults1.
Approximately 15 to $20 \%$ of SLE cases begin before the age of 19 years2. The incidence of lupus is not known but varies by location \& ethinic difference. Lupus is characterized by production of auto-antibodies. Polyclonal activation by nonspecific response to antigenic stimuli such as viral agents or following loss of either B-cell immune tolerance to self-antigens or suppressor T-cell function may produce autoantibody. Other mechanisms like defect in macrophage phagocytosis and production of immune complexes have also been described3. Various antibodies are found in SLE like ANA, Anti-dsDNA, anti SS-A (anti-Ro), anti-SS-B (anti-La), anti-Sm, anti-phospholipids antibody and others. It has been 
shown that thyroid dysfunction may also be present in pSLE cases. The patients with SLE may be euthyroid, subclinical hypothyroid, overt hypothyroid or hyperthyroid. It is suggested that patients with autoimmune thyroid disorders may develop SLE or vice-versa4. The association between systemic lupus erythematosus (SLE) and thyroid abnormalities was first described in 1961 and showed that the presence of thyroid disturbance appeared to be more frequent in SLE patients than in the general population5. Anti-thyroid antibodies were more frequent in SLE cases ${ }^{6}$. The vast majority of hypothyroidism in pSLE results from autoimmune thyroiditis ${ }^{7}$.

The autoimmune process is believed to begin with activation of CD4+T-helper lymphocytes specific for thyroid antigens. Activated CD4+ T lymphocytes recruit cytotoxic $(\mathrm{CD} 8+) \mathrm{T}$ cells as well as B cells into the thyroid gland. Thyroid cell destruction occurs through multiple mechanisms: cytotoxic $\mathrm{T}$ cells that induce apoptosis; cytotoxic antibodies that fix complement and cause thyroid cell lysis and antibody-dependent cell-mediated cytotoxicity (ADCC) involving natural killer cells ${ }^{7}$. Subclinical hypothyroidism $(\mathrm{SCH})$ is associated with a pro-atherogenic dyslipidemia and increased risk of cardiovascular disease ${ }^{8}$. These effects are greater at higher TSH levels ${ }^{9}$.

To date, no study has been conducted on thyroid abnormalities among pediatric SLE patients in Bangladesh. The aim of this study was to assess thyroid function and thyroid auto-antibodies in pediatric SLE patients so that early detection and management of these associated thyroid disorders can be ensured.

\section{Methods}

This was a cross sectional study. The study was done in the Department of Pediatrics, Bangabandhu Sheikh Mujib Medical University (BSMMU) and National Institute of Nuclear Medicine and Allied Science (NINMAS), BSMMU, Dhaka from January 2013to July total number of A .201456 pediatric systemic lupus erythematosus (pSLE) patients attended pediatric rheumatology follow up clinic and in-patient department of pediatrics, BSMMU fulfilling American College of Rheumatology (ACR) 1997 revised criteria1. Among them 50 patients were enrolled in the study purposively, who fulfilled the inclusion criteria. The pSLE patients previously diagnosed having thyroid dysfunction and severe malnutrition were excluded from study. Patients having inactive disease were also excluded from study. Sixteen age and sex matched apparently healthy patients who did not have any chronic or severe diseases and severe malnutrition were enrolled as reference group from the pediatric out patient department.

Data were collected in a pre-designed structured questionnaire. Relevant clinical examination and necessary laboratory investigations for diagnosis of SLE were done after taking consent from parents. Baseline laboratory investigations like $\mathrm{Hb} \%$, total white cell count, differentials, platelet count, ESR, serum creatinine, chest x-ray, ANA (immunofluorescence; Hep-2 cell method), urine routine examination, lipid profile, 24 hour urine total protein (UTP), C3 \& C4, coomb's test, anti-dsDNA and anti-cardiolipin antibody were done to all patients.

Investigations for this study included thyroid functions $\left(\mathrm{T}_{3}\right.$, $\mathrm{T}_{4}, \mathrm{TSH}$ ) and thyroid anti-bodies (Anti-TPO \& Anti-TG). Thyroid function tests were analyzed and thyroid status were classified as euthyroid, subclinical hypothyroid, hypothyroid and euthyroid sick syndrome. Total tri-iodothyronine $\left(\mathrm{T}_{3}\right)$, total thyroxine $\left(\mathrm{T}_{4}\right)$ and thyroid stimulating hormone (TSH) were measured by immune radiometric assay using IMK-422, IMK-419 and IMK-432 respectively. Thyroid peroxidase (TPO) was measured by ${ }^{125} \mathrm{I}-\mathrm{TPOAb}$ radio immuno assay (RIA) kit IMK-417. Thyroglobulin (anti-TG) was measured by radioimmunoassay (RIA) Kit IMK-476. Disease activity was measured by systemic lupus erythematosus disease activity index (SLEDAI) ${ }^{10}$.

The data were analyzed by SPSS window version 16 which included descriptive statistics, Mann-Whitney test and Fisher exact test. $\mathrm{P}$ value $<0.05$ with $95 \%$ confidence interval was considered as the level of statistical significance.

\section{Working Definitions Used for the Study Are Given Below ${ }^{11}$}

Thyroid disorders: Any abnormality in thyroid function which includes:

a) Hypothyroidism: Defined as raised TSH level along with a decreased serum thyroid hormone level (any of $\mathrm{T}_{3}$ or $\mathrm{T}_{4}$ or both).

b) Subclinical hypothyroidism: Defined as raised TSH level along with normal serum thyroid hormone levels.

c) Hyperthyroidism: Defined as high $\mathrm{T}_{3}$ and low TSH.

d) Euthyroid sick syndrome: Defined as low $\mathrm{T}_{4}$ or low $\mathrm{T}_{3}$ and normal TSH.

Euthyroid: Normal levels of both T3 and T4 along with normal TSH level.

The normal value of thyroid hormones and thyroid antibodies are given below ${ }^{12,13,14}$ :

Serum $\mathrm{T}_{3}: 0.8-2.3 \mathrm{ng} / \mathrm{ml}$

Serum $\mathrm{T}_{4:}: 42.0-135.0 \mathrm{ng} / \mathrm{ml}$

Serum TSH: 0.3- 5.0mIU/L

Serum anti-TPO Antibody: $\leq 15 \mathrm{U} / \mathrm{ml}$.

Serum anti-TG antibody: $\leq 30 \%$ (of total detected anti-body)

\section{Results}

Among the total number of 50 pSLE cases male: female ratio was 1:24 and among 16 reference group the ratio was 1:15 in this study. The mean age range was $11.9 \pm 3.1$ among cases and $8.6 \pm 4.7$ among reference group.

Frequency of hypothyroidism, subclinical hypothyroidism, euthyroid sick syndrome and euthyroid cases was $6 \%, 8 \%, 4 \%$ and $82 \%$ respectively among the studied pSLE cases. On the other hand $100 \%$ of the reference groups children were euthyroid (Table-1). 
Table 1. Thyroid Disorders among pSLE Patients $(n=50)$ and Reference Group (n=16).

\begin{tabular}{lll}
\hline & Number & Sex \\
\hline Hypothyroidism & $3(6 \%)$ & Female \\
Subclinical & $4(8 \%)$ & Female \\
Hypothyroidism & $2(4 \%)$ & Female \\
Euthyroid Sick Syndrome & $41(82 \%)$ & Female 39, Male 2 \\
Euthyroid Patients & 16 (euthyroid) & Female 15, Male 1 \\
Reference Group &
\end{tabular}

In Table- 2 it is shown that anti-TPO antibody was positive in $48 \%$ of pSLE cases and $18.7 \%$ of reference group. Anti-TG antibody was also much higher (32\%) among pSLE cases than reference group $(6.2 \%)$. Mean anti-TPO titre and mean anti-TG titre was significantly higher among cases than reference group $(\mathrm{p}<0.001)$. All the patients having positive
anti-TG antibody also had positive anti-TPO antibody. Both the antibody positivity and total antibody positivity was also significantly higher among the cases than the reference group.

Table 2. Frequency and Mean Level of Thyroid Antibodies among pSLE cases and Reference Group $(n=50+16)$.

\begin{tabular}{llll}
\hline & $\begin{array}{l}\text { pSLE cases } \\
(\mathbf{n = 5 0 )}\end{array}$ & $\begin{array}{l}\text { Reference } \\
\text { Group }(\mathbf{n = 1 6 )}\end{array}$ & P value \\
& Number, $(\%)$ & $3(18.7)$ & \\
\hline Anti-TPO antibody & $24(48)$ & $30.2 \pm 17.4$ & 0.001 \\
Mean level (SD) & $87.3 \pm 154.9$ & $1(6.2)$ & \\
Anti-TG antibody & $16(32)$ & 33.8 & 0.001 \\
Mean level (SD) & $54.3 \pm 18.5$ & $1(6.2)$ & 0.001 \\
Both antibody & $13(26)$ & $3(18.7)$ & 0.001 \\
Total antibody & $27(54)$ & & \\
\hline
\end{tabular}

Table 3. Frequency of Thyroid Antibodies Among pSLE cases in Relation to Thyroid Function ( $n=50)$.

\begin{tabular}{lllll}
\hline Parameters & Hypothyroidism n (\%) & Subclinical hypothyroidism n (\%) & Euthyroid n (\%) & Euthyroid Sick Syndrome n (\%) \\
\hline Number & 3 & 4 & 41 & 2 \\
Anti-TPO (\%) & $3(100)$ & $4(100)$ & $17(41.46)$ & 0 \\
Anti-TG antibody (\%) & $3(100)$ & $2(50)$ & $11(26.8)$ & 0 \\
Both antibodies (\%) & $3(100)$ & $2(50)$ & $8(19.5)$ & 0 \\
No antibody (\%) & 0 & 0 & $5(12.2)$ & 0 \\
\hline
\end{tabular}

It is evident from Table-3 that $100 \%$ patients of hypothyroidism had positive anti-TPO antibody and anti-TG antibody. On the other hand, among the sub clinical hypothyroidism patients $100 \%$ had positive anti-TPO but
anti-TG antibody was positive in $50 \%$ cases. Among euthyroid patients $41.46 \%$ had positive Anti-TPO antibodies and $12.2 \%$ did not have any antibody.

Table 4. SLEDAI Score, Level of Thyroid Hormones and Thyroid Auto-antibodies in Relation to Thyroid Status of pSLE Patients ( $n=48$ ).

\begin{tabular}{lllc}
\hline & $\begin{array}{l}\text { pSLE with Euthyroid } \\
\text { function }(\mathbf{n = 4 1})\end{array}$ & $\begin{array}{l}\text { pSLE with Subclinical } \\
\text { Hypothyroidism (n=4) }\end{array}$ & pSLE with Hypothyroidism (n=3) \\
\hline PLEDAI Score Range & $9-38$ & $11-25$ & $12-27$ \\
Mean (SD) & $16.9 \pm 7.6$ & $19.8 \pm 6.7$ & $20.0 \pm 7.5$ \\
$\mathrm{~T}_{3}(\mathrm{ng} / \mathrm{ml})$ Range & $0.8-3.4$ & $0.97-1.9$ & $0.70-0.8$ \\
Mean (SD) & $1.4 \pm 0.6$ & $1.27 \pm 0.5$ & $0.8 \pm 0.2$ \\
$\mathrm{~T}_{4}(\mathrm{ng} / \mathrm{ml})$ Range & $48.5-130.9$ & $50.01-77.4$ & $38-40.1$ \\
Mean (SD) & $88.9 \pm 25.2$ & $62.84 \pm 11.5$ & $42.6 \pm 6.4$ \\
TSH (mIU/L) Range & $0.5-3.7$ & $5.3-8.4$ & $6.5-12.5$ \\
Mean (SD) & $2.0 \pm 1.4$ & $5.6 \pm 0.3$ & $8.9 \pm 2.4$ \\
Anti-TPO (U/ml) Range & $1.1-635.7$ & $16.90-32.0$ & $145-492.6$ \\
Mean (SD) & $34.4 \pm 99.7$ & $21.4 \pm 7.2$ & $262.5 \pm 199.3$ \\
Anti TG(\%) Range & $1.5-76.7$ & $1.39-55.32$ & 0.006 \\
Mean(SD) & $18.2 \pm 23.3$ & $14.9 \pm 26.9$ & 0.001 \\
\hline
\end{tabular}

The SLEDAI score and T3 level were not significantly different between euthyroid, hypothyroid and subclinical hypothyroid pSLE patients $(\mathrm{P}>0.05)$. But $\mathrm{T}_{4}$, anti-TPO, Anti-TG and TSH levels were significantly different between euthyroid, subclinical hypothyroid and hypothyroid pSLE patients (Table-4).

\section{Discussion}

Thyroid auto-antibodies may cause autoimmune thyroiditis resulting in hypothyroidism, subclinical hypothyroidism, euthyroid sick syndrome and even hyperthyroidism in SLE patients. The vast majority of hypothyroidism in pSLE results from autoimmune thyroiditis ${ }^{7}$. SLE patients have a higher frequency of biochemical abnormalities of thyroid function even when they don't have clinical disease ${ }^{15}$. The underlying pathogenesis for this association is not clear ${ }^{16}$.

In this study $54 \%$ of paediatric SLE (pSLE) had thyroid auto-antibodies while among the reference group thyroid autoantibodies were found in only $18.7 \%$. Individual analysis of this study found, anti-TPO antibody and anti-TG antibody were also significantly higher among pSLE patients than reference group. Other studies reported presence of thyroid auto-antibodies in $46.7 \%, 27 \%$ and $20 \%$ SLE cases ${ }^{17,18,19}$. Our result showed that both the frequency and mean titre of positive thyroid auto-anti bodies were significantly higher among the cases than reference group. Other auto-antibodies like thyroid stimulating hormone receptor (TSHR) antibody 
and thyroid stimulating immunoglobulin (TSI) were not done in this study. Overall, it was found that, there was a trend towards more frequent anti-TPO antibody positivity than anti-TG among both the cases and reference group. This trend had also been observed in earlier studies ${ }^{6,20}$.

It is reported that anti-TPO antibody may be present in $85-100 \%$ cases of SLE with thyroid disorder ${ }^{21}$. Both the hypothyroid and subclinical hypothyroid pSLE patients were $100 \%$ positive for anti-TPO antibodies whereas euthyroid patients had only $41 \%$ anti-TPO antibodies. However, the prevalence of anti-TPO antibody in SLE patients with thyroid disorder was reported as $27 \%, 23.2 \%, 3.7 \%, 15 \%$ and $25.6 \%$ by Chan et $\mathrm{al}^{22}$, Pyne and Isenberg ${ }^{20}$, El-Sherif et $\mathrm{al}^{23}$, Al-Saleh et $\mathrm{al}^{24}$ and Park et $\mathrm{al}^{18}$ studies. The frequency of antibody positivity among the reference group was higher than healthy Australian population $(12.4 \%)^{25}$, healthy Kuwaiti population $(3.1 \%)^{26}$ and Omanis population $(5.7 \%)^{27}$. The reason for this variation is not clearly understood, but it could be explained as occurring due to variation of ethnic population, difference in age, gender, anti-TPO assays method and unknown genetic or environmental factors.

In the present study, the higher frequency of positivity and mean levels of anti-TPO antibody among pSLE patients (hypothyroidism, subclinical hypothyroidism and euthyroid cases) may suggest that anti-TPO antibody could have pathogenic role in thyroid disorder in lupus children. It might cause the development of autoimmune thyroid disease, but this remains to be verified with longitudinal follow up studies. Another reason might be the fact that anti-TPO antibody possibly is a part of the polyclonal hypergamaglobulinaemia observed in SLE patients ${ }^{28}$.

This study found that $18 \%$ patients among 50 pediatric SLE cases had thyroid disorders but none of the reference group had thyroid disorder. In an Egyptian study ${ }^{23}$, thyroid disorders were found among $50 \%$ of pSLE patients which was higher than this study. This difference may be explained by the facts that the present study had a small sample size and lower age group of patients.

Presence of hypothyroidism among pSLE cases in the current study was comparable to Miller et al study ${ }^{19}$ where hypothyroidism was found in $6.6 \%$, and Pyne and Ienberg study ${ }^{20}$ where it was found in $5.7 \%$ cases. Kakehasi et $\mathrm{al}^{5}$ in their study found $4 \%$ hypothyroidism among SLE patients and Tsai et $\mathrm{al}^{17}$ found it as $8.8 \%$. Park et $\mathrm{al}^{18}$ and Weetman and Walport ${ }^{29}$ in their study found the incidence much higher $(9.5 \%$ and 24\%). A recent study done in Egypt found the prevalence of subclinical and clinical hypothyroidism in SLE patients as $10 \%$ and $4 \%{ }^{30}$. These variations of hypothyroidism may also be related to ethnic background of patients, age group of the study population, sample size and the sensitivity of tests and kits used to detect the hormone levels.

Subclinical hypothyroidism in pSLE patients in our study was comparable to the findings of Kakehasi et $\mathrm{al}^{5}(10 \%)$ and El-Sharif et $\mathrm{al}^{23}(10 \%)$ study but higher than Park et al ${ }^{18}$ study where subclinical hypothyroidism was found in $1.6 \%$ among Korean adult SLE patients. However it was less than Miller et $\mathrm{al}^{19}(39 \%)$, Al-Saleh et $\mathrm{al}^{24}(13.7 \%)$ and Kumar et $\mathrm{al}^{31}(12 \%)$ studies done in SLE patients. Chan et $\mathrm{al}^{22}$ in their study also reported that the prevalence of subclinical hypothyroidism was more than hypothyroidism among SLE cases. Our findings substantiated the report showing presence of hypothyroidism in $6 \%$ and subclinical hypothyroidism in $8 \%$ of pSLE patients. All the pSLE cases with hypothyroidism and subclinical hypothyroidism had positive anti-TPO antibody supporting the fact that production of auto-antibodies are responsible for thyroid disease in SLE.

In this study none of the pSLE patients having euthyroid sick syndrome had positive thyroid antibodies. In contrast to our study, Al-Awadhi et $\mathrm{al}^{26}$ and Kumar et $\mathrm{al}^{31}$ found higher frequencies of euthyroid sick syndrome among SLE cases. No euthyroid sick syndrome was reported by Goh and wang ${ }^{4}$, Miller et $\mathrm{al}^{19}$, Park et $\mathrm{al}^{18}$ and Pyne and Isenberg ${ }^{20}$.

Although, most of the studies have shown that the prevalence of hyperthyroidism in SLE patients were greater than general population, the issue is still debatable ${ }^{11}$. In this study, hyperthyroidism was not detected among the pSLE patients as well as among the reference group. Some studies suggested that there was no increase in prevalence of hyperthyroidism in SLE patients ${ }^{19,32}$. However, Chan et $\mathrm{al}^{22}$ and Porkodi et $\mathrm{al}^{6}$ found a significant number of hyperthyroidism cases in SLE patients. It is to be noted that our study was done among pediatric SLE cases but most of the studies were done in adult SLE patients except a few ${ }^{28}$. It is reported that $\mathrm{pSLE}$ have different presentation than adult SLE patients $^{33}$. Though it is established that involvement of internal organ and severity is higher in pSLE patients than adult but little information regarding thyroid involvement among pediatric SLE patients is known. So, it is difficult to explain the reasons clearly.

\section{Conclusion}

Present study demonstrated that thyroid disorders were detected in $18 \%$ of pSLE patients. Most of the patients with thyroid disorders had positive anti-thyroid antibodies (54\%). Frequency of anti-TPO positivity was much higher than that of anti-TG positivity. Hypothyroidism and subclinical hypothyroidism was found in $6 \%$ and $8 \%$ of pSLE patients respectively. So from this study it may be concluded that assessment of thyroid function in pSLE patients as a part of biochemical and immunological profiles may help in early detection of associated thyroid disorders.

\section{Authors' Contributions}

\section{Satya Narayan Chaudhary}

Contribution: Conception of the study, design and drafting, data collection, analysis, interpretation and statistical analysis. email: drsatyan@gmail.com (Corresponding Author)

\section{Shahana Akhter Rahman}

Contribution: Conception of the study, design, analysis, interpretation and revision of mauuscript.

3. Mohammad Imnul Islam

Contribution- Conception and drafting of manuscript, 
analysis \& interpretation.

4. Suraiya Begum

Contribution- Analysis of results and revision of manuscript.

5. Manik Kumar Talukdar

Contribution- Analysis of results \& interpretation.

6. Mohammad Israque Hossain Ansari

Contribution- Data collection and Immune assay.

7. Mizanul Hasan

Contribution - Data collection and Immune assay.

\section{Authors' Information}

Dr Satya Narayan Chaudhary, MD Peditrics. He was a working as a Medical Officer, Paediatrics, under Government of Nepal. Currently he has completed his MD in Paediatrics and working as a senior resident in Bangabandhu Sheikh Mujib Medical University, Dhaka, Bangladesh.

\section{Acknowledgements}

All the Pediatricians and Residents of Department of Pediatrics, Bangabadhu Sheikh Mujib Medical University. All the children with SLE and their parents. All the doctors, technicians and staffs of National Institue of Nuclear Medicine and Allied Science.

\section{References}

[1] Ardoin SP, Schanberg LE. Systemic Lupus Erythematosus. In: Kliegman RM, Stanton BF, St.Game JW, Schor NF, Behrman RE, editors. Nelson Textbook of pediatrics. $19^{\text {th }}$ edition Philadelphia: Elsevier Saunders; 2012. P. 841-46.

[2] Silverman E, Eddy A. Systemic lupus erythematosus. In: Cassidy JM, Petty RE, Laxer RM, Lindaley CB editors. Textbook of Pediatric Rheumatology. Philadelphia: Elsevier Saunders; 2011. P. 315-343.

[3] Klein-Gitelman MS, Miller ML. Systemic lupus erythematosus In: Behrman RE, Kleigman RM Jenson HB, Stanton BF, editors. Nelson Textbook of Pediatrics. $18^{\text {th }}$ edition. Philadelphia: Elsevier Saunders; 2007. p. 809-813.

[4] Goh KL, Wang F. Thyroid disorders in systemic lupus erythematosus. Annals of the Rheumatic Diseases 1986; 45: 579-583.

[5] Kakehasi AM, Dias VN, Duarte JE, Lanna CCD, Carvalho MAP. Thyroid abnormalities in systemic lupus erythematous: a study in 100 Brazilian patients. Rev Bras Reumatol 2006; 46: 375-379.

[6] Porkodi R, Ramesh S, Mahesh A, Kanakarani P, Rajendran C. Thyroid function and auto-antibodies in Egyptian patient with systemic lupus erythematosus and rheumatoid arthritis. J. Indian Rheumatol Assoc 2004; 12: 88-92.

[7] Weetman AP. Chronic autoimmune thyroiditis. In: Breverman LE, Utiger RD editors. The thyroid: A fundamental and clinical text. Philadelphia, Lippincott Williams and wilkins; 2000. P. 721-732.
[8] Chu JW, Crapo LM. Should mild subclinical hypothyroidism be treated? Am J Med 2002; 112: 422-3.

[9] Kahaly GJ. Cardiovascular and atherogenic aspects of subclinical hypothyroidism. Thyroid 2000; 10: 665-79.

[10] Brunner HI, Feldman BM, Bombardier C, Silverman ED. Sensitivity of the Systemic lupus erythematosus disease activity index, British Isles lupus assessment group index, and Systemic lupus activity measure in the evaluation of clinical change in childhood onset Systemic lupus erythematosus. Arthritis Rheum 1999; 42: 1354-60.

[11] Mousa AA, Ghonem M, Hegazy A, El-Baoemy AA, El-daisty A. Thyroid function and auto-antibodies in Egyptian patients with systemic lupus erythematosus and rheumatoid arthritis. Trends in Medical Reasearch 2012; 7: 25-33.

[12] Baloch Z, Carayon P, Conte-Devolex B, Demer LM, Feldt-Rasmussen U, Henry JF, et al. Guidelines Committee, National Academy of Clinical Biochemistry (NACB). Laboratory medicine practice guidelines (LMPG): Laboratory support for the diagnosis and monitoring of thyroid disease. Thyroid 2003; 13( 1): 3-126.

[13] Oppenheimer JH. Role of plasma protein in the binding, distribution and metabolism of thyroid hormone. New England Journal of Med 1968; 278: 1153-62. Waite KY, Mabery GF, Ma $\mathrm{G}$, Estam CJ. Immunoradiometric assay with use of magnetizableparticles. Clin chem 1986; 32,10: 1966-8.

[14] Waite KY, Mabery GF, Ma G, Estam CJ. Immunoradiometric assay with use of magnetizable particles: Measurement of thyrotropin in blood spot to serum for neonatal hypothyroidism. Clin chem 1986; 32(10): 1966-8.

[15] Weetman AP. Non-thyroid autoantibodies in autoimmune thyroid disease. Best pract Res clin Endocrinal metab. 2005; 19: 17-32.

[16] Karmaker CK, Toruinho TF, Castro WP. Association between systemic lupus erythematosus, rheumatoid arthritis, hyperprolactenemia and thyroid antibodies. Arch med res 2005; 36: $54-58$.

[17] Tsai RT, Chang TC, Wang CR, Chuang CY, Chen CY. Thyroid disorder in Chinese patients with systemic lupus erythematosu. Rheumatol Internatioanl 1993; 13: 9-13.

[18] Park DJ, Cho CS, Lee SH, Park SH, Kim, HY. Thyroid disorder in Korean patients with systemic lupus erythematosus. Scan J. Rheumatol 1995; 24: 13-17.

[19] Miller FW, Moore GF, Weintraub BD and Steinberg AD. Prevalence of thyroid disease and abnormal thyroid function test results in patients with systemic lupus erythematosus. Arthritis Rheumatism 1987; 30: 1124-1131.

[20] Pyne D, Isenberg DA. Autoimmune thyroid disease in systemic lupus erythematosus. Ann Rheum Dis. 2002; 1: 70-2.

[21] Engler H, Staub JJ, Althaus B, Ryff-de Leche A, Gerber, H. Assessment of antithyroglobulin and anti-microsomal autoantibodies in patients with autoimmune thyroid disease: comparison of haemagglutination assay, enzyme-linked immunoassay and radioligand assay. Clin Chim Acta. 1989; 179 (3): 251-263.

[22] Chan AT, Al-Saffar Z, Buknail RC. Thyroid disease in systemic lupus erythematosus and rheumatoid arthritis. Rheumatology 2001; 40(3): 353-354. 
[23] El-Sherif WT, El-Gendi SS, Ashmawy MM, Ahmed HM, Salma MM. Thyroid disorder and auto-antibodies in systemic lupus erythematosus and rheumatoid arthritis. Egypt J Immunol 2004; 11: 81-90.

[24] Al-Saleh J, Jassim V, El-Sayed M, Saleh N, Harb D. Clinical and immunological manifestations in 151 SLE patients living in Dubai. Lupus 2008; 17: 62-66.

[25] O’Leary PC, Edema PH, Micheeli VP, Leedman PJ, Chew GT, et al. Investigations of thyroid hormones and antibodies based on a community health survey: the Busselton thyroid study. Clinical endocrinology 2006; 64: 97-104.

[26] Al-Awadhi AM, Olusi S, Hasan EA, Abdullah A. Frequency of abnormal thyroid function in Kuwaiti Arabs autoimmune disease. Med Princ Pract 2008; 17: 61-65.

[27] Al-Jabri AA, Al-Belushi MS, Nsanze H. Frequency and levels of autoantibodies in healthy adult Omanis. Ann Saudi Med 2003; 23(6): 372-6.

[28] El-Ghoneimy DH, Awad KS, Soliman AD, El-wahab RMA. Subclinical hypothyroidism among Egyptian children with systemic lupus erythematosus. Egypt J Pediatr Allergy Immunol 2011; 9(2): 87-92.

[29] Weetman AP, Walport MJ. Association of autoimmune thyroiditis with systemic lupus erythromatosus. Br. J Rheumatol 1987; 26: 359-61.

[30] El-Hadidi KT, Mansour MA, El-Wakd MM, El-Emary AE. Thyroid dysfunction and anti-thyroid antibodies in Egyptian patients with systemic lupus erythematosus: Correlation with clinical musculoskeletal manifestations. The Egyptian Rheumatologist 2014; 36: 173-178.

[31] Kumar K, Kole AK, Karmakar PS, Ghosh A. The spectrum of thyroid disorders in systemic lupus erythematosus. Rheumatol Int 2010; 32 (1): 73-78.

[32] Boey WL, Fong PH, Lee JS, Nag WY, Thaia AC. Autoimmune thyroid disorder in Singapore lupus. Lupus 1993; 2: 51-54.

[33] Mina R, Brunner HI. Pediatric lupus - Are there differences in presentation, genetics, response to therapy, damage accrual compared to adult lupus? Rheum Dis Clin N Am 2010; 36(1): 53-80. 